\title{
Costumes, tradições e usos dos adolescentes da cidade de Barreirinhas (MA): há influências comportamentais dos visitantes?
}

\section{Costums, traditions and uses of the teenagers at Barreirinhas' city (MA, Brazil): are there any comportamental influences of the visitors?}

\author{
Marcelo Aragão Saldanha, Leonardo Augusto Lobato Bello, \\ Sílvia Helena Ribeiro Cruz
}

RESUMO: O objetivo do trabalho instalado é discorrer sobre aspectos gerais dos costumes, tradições e usos dos adolescentes, habitantes da cidade de Barreirinhas, no estado do Maranhão - ela que é a porta de acesso a uma das belezas naturais mais singulares do mundo, o Parque Nacional dos Lençóis Maranhenses. Para tanto, no que concerne a busca das informações inerentes, se estabelece (desde a pesquisa de campo, acontecida nas salas de aula do Instituto Federal do Maranhão, campus Barreirinhas) a metodologia quantitativa/qualitativa (dada a aplicação de um questionário estruturado e de todo analisado) que fundamenta a macro indagação -Há influências comportamentais dos visitantes sobre estes, visto a permanente proximidade entre ambos? Quanto aos resultados obtidos, estes apontam para as evidências de uma afirmativa, que culmina com o efeito imitação dos novos hábitos forasteiros, em crescente substituição aqueles ora vigentes.

PALAVRAS-CHAVE: Costumes; Adolescentes; Barreirinhas; Influências Comportamentais; Visitantes

\section{ABSTRACT}

The purpose of the work is to discuss general aspects of customs, traditions and uses of adolescents, inhabitants of the city of Barreirinhas in the state of Maranhão - which is the gateway to one of the most unique beauties in the world, Lençóis Maranhenses National Park. To do so, as far as the search for inherent information is concerned, the quantitative / qualitative methodology (from the field research carried out in the Federal University of Maranhão classrooms Barreirinhas) is established (given the application of a structured questionnaire and all analyzed ) that underlies the macro inquiry - Are there behavioral influences of visitors on these, given the permanent proximity between them? As for the results obtained, they point to the evidence of an affirmation, culminating with the imitation effect of new alien habits, in increasing substitution those now in force.

KEYWORDS: Costums; Adolescents; Barreirinhas; Behavioral Influences; Visitors. 


\section{Introdução}

Este artigo objetiva discorrer sobre aspectos gerais dos costumes, tradições e usos dos adolescentes, habitantes da cidade de Barreirinhas distante cerca de 270 quilômetros da capital do estado do Maranhão e porta de entrada do Parque Nacional dos Lençóis Maranhenses, com os seus 150 mil hectares de dunas de areias alvas e finas que se movem ao sabor dos ventos e lagoas cristalinas e profundas, fundamentando assim, discussões sequenciais acerca dos impactos culturais do fenômeno turístico neste destino verde, indo ao encontro da resposta (devidamente fundamentada) da macro indagação - Há influências comportamentais dos visitantes sobre estes, visto a permanente proximidade entre ambos?

O trabalho proposto é didaticamente segmentado em três abordagens distintas e complementares. Na primeira delas, caracteriza-se a cidade objeto do estudo, a partir de entendimentos socioespacial e histórico, inserindo-se nele, substratos (notadamente ampliados) culturais dos adolescentes, que momentaneamente vivem nela. Na sequência, desde um contraponto, aproxima-se o visitante/turista (dado o seu comportamento "diferente") à natural geração de impactos na comunidade receptora, sobretudo, junto aos mais jovens. Por fim, apresenta-se os resultados da pesquisa de campo, utilizando-se das respostas obtidas, visto a aplicação de um questionário estruturado, composto de 13 indagações - sendo 11 delas objetivas e 02 subjetivas, junto aos adolescentes/alunos do Instituto Federal do Maranhão campus Barreirinhas, apontando os preliminares resultados deste trabalho científico para a conclusão de uma situação entendida como afirmativa.

\section{A cidade turística de Barreirinhas: caracterização socioespacial e histórica}

Estando localizada no nordeste do estado do Maranhão, na mesorregião do Norte, na microrregião da Baixada Oriental ou dos Lençóis Maranhenses e distando cerca de $270 \mathrm{~km}$ a leste da capital São Luís, segundo os dados do IBGE (2015), a cidade de Barreirinhas, geograficamente muito interiorana, detém uma área territorial de aproximadamente $3025 \mathrm{~km}^{2}$.

Com apenas duas estações climáticas no ano (o inverno chuvoso e o verão de calor intenso) é uma região extrativista, rica em plantações do buriti muito usado pelos nativos para a cobertura das suas casas e na produção de doces.

A pesca ainda responde por um papel importante junto a economia do lugar, especialmente no que tange a subsistência das comunidades mais pobres - habitualmente, famílias inteiras (inclusive, junto dos seus filhos ainda crianças e adolescentes) são vistas comercializando os seus excedentes no cais da cidade, à beira do rio Preguiças, ele que é a principal via fluvial perene da região.

Ao lado desta prática, os citadinos também sobrevivem do cultivo da castanha do caju, visto a exportação (in natura) para o estado do Ceará, sendo ela, o mais importante produto agrícola do lugar, assim como da fabricação artesanal da farinha de mandioca. 
O Índice de Desenvolvimento Humano do Município (IDHM), em 2010, foi de 0,570 - considerado de baixa escala, se comparado com aquele da capital São Luís, em mesmo ano, de 0,768 (alta escala).

Desde o censo 2017, sua população estimada é de 62.458 mil habitantes residentes (predominantemente católicos - cerca de 71,65\%), e deste quantitativo, quase 21 mil figura uma gente jovem, que vive em um núcleo urbano minimamente organizado, estando a maioria das residências alocadas na centralidade municipal e providas de água encanada, da coleta regular de lixo e de rede elétrica - um contingente populacional sazonal, que só aumenta em tempos de feriados e férias escolares.

Junto dos veículos, as bicicletas e as motocicletas convivem cada vez mais, com as linhas regulares e tradicionais de caminhonetes tracionadas, que no município, ainda fazem as vezes dos ônibus, todos entendidos como os meios de transporte mais usados pela população autóctone, circulando junto a um trânsito que beira o caos, uma vez que ainda completamente desprovido de quaisquer disciplinas (atualmente, não se contabiliza mais que uma dezena de semáforos em funcionamento, desde os bairros notadamente centrais e crianças podem ser vistas dirigindo quadriciclos, com o devido conhecimento dos seus pais).

Ainda que em número pouco expressivo, são vistas na sede (e também nos povoados vizinhos), unidades escolares de ensinos Fundamental e Médio. Em 2010, segundo o Atlas do Desenvolvimento Humano no Brasil, a proporção de crianças de 11 a 13 anos frequentando o último ano do ensino fundamental é de $85,02 \%$, já aquela de jovens entre 15 a 17 anos com o ensino fundamental completo é de $41,97 \%$, ao passo que aqueles providos da faixa etária de 18 a 20 anos, com o ensino médio completo é de $16,80 \%$. Dos jovens adultos (18 a 24 anos), apenas 2,93\% estavam cursando o ensino superior.

Vale ressaltar a recente instalação de um campus do Instituto Federal do Maranhão (IFMA), munido da oferta de cursos médios profissionalizantes diversos, inseridos em dois macro eixos, o de Agronegócios e o de Hospitalidade e Turismo. No início do ano de 2014, o curso superior de Licenciatura em Ciências Biológicas passou a constar do "portfólio" das vagas deste estabelecimento de formação.

Já o comércio local é cada vez mais multifacetado, ainda existindo as antigas mercearias que se utilizam da caderneta para a tomada dos pedidos a serem pagos no mês seguinte, como também, as lojas grifadas de cosméticos, as "lan houses" e as operadoras de telefonia móvel (estas, apinhadas de adolescentes ávidos pela aquisição dos mais recentes lançamentos de aparelhos celulares).

Até o ano de 2012, apenas uma agência do Banco do Brasil existia na cidade, tendo sido ela inaugurada, desde 1980. Agora, além desta, outras tantas surgiram, a exemplo do Banco Bradesco, do Banco do Nordeste e da Caixa Econômica Federal, tudo em função do dinheiro mais circulante, advindo sobremaneira da nova economia do Turismo. 
E com o povoamento do município datado de 1850, tendo sido elevada a categoria de Paróquia em 1858, Barreirinhas foi segundo Ramos (2008, p.34) "Emancipada como cidade em 1938, fazendo parte da comarca de Araióses, e só na década de 70 experimentou um notável crescimento econômico, quando a Petrobrás fincou ali a sua bandeira, ensaiando a prospecção de petróleo e gás natural". Desta forma, o lugar tomado de otimismo, vislumbrava o término de todo o seu isolamento histórico.

Quanto a sua inclinação para a atividade turística, esta se revelou no fim da década de 90, dado o interesse da então gestão pública estadual, materializada no polêmico Plano de Desenvolvimento Integral do Turismo - o Plano Maior, de revelar para todo o mundo, o que comercialmente se constituía de um dos "Segredos do Maranhão", portanto, o Parque Nacional dos Lençóis Maranhenses, também nela incrustado. Acerca deste cenário, Yázigi (2003, p.127) trata com bastante clareza:

A estradinha de terra ganha asfalto; surge uma pequena pousada, um posto de gasolina, os prestadores de serviços turísticos, um restaurante; os carros chegam e os loteamentos também. A pressa em ganhar dinheiro fácil, aliada a displicência administrativa, que interpreta todo início de empreendimento, como fator de progresso.

No que tange aos deslocamentos para o destino, até o início do ano de 2002, que antecede a construção da MA-402, a Translitorânea, estrada que interliga a cidade às rodovias BR 135 e 222, chegar à Barreirinhas por meio do acesso literal por estrada de terra, significava viajar desconfortavelmente $\mathrm{e}$ de maneira muito perigosa, visto sobretudo, as travessias rudimentares dos igarapés e riachos, por um tempo aproximado de nove horas, em meio ao calor e a poeira, então inerentes características do caminho. De acordo com Ramos (2008, p.141) com a construção da Translitorânea, "[...] o trajeto foi encurtado em mais de $100 \mathrm{~km}$ e impulsionou, consideravelmente o Turismo na região".

E como consequência de todo este cenário desenvolvimentista recente, tratando-se a partir de uma outra abordagem, de todo relacionada à reconfiguração do território, observa-se que o fluxo dos habitantes da cidade de Barreirinhas é cada vez mais crescente (especialmente daqueles mais jovens), uma vez que muitos trocaram o campo e a vizinhança ribeirinha pela sede, para então trabalhar neste setor, e aqueles que buscavam a capital, na disposição de ingressarem em uma atividade laboral diferente, permaneceram na cidade.

Acerca disto Ruschmann (1997, p.19) ressalta, em sobremaneira, a maior fixação da população autóctone - o êxodo para os grandes centros urbanos, normalmente deixa de acontecer dadas "[...] as inúmeras oportunidades de emprego, trabalho e renda que surgem no próprio lugar, ele que deve ser entendido como um sítio de pertencimento [...]" - porquê de orgulho instalado, onde os costumes, as crenças e as tradições, devem 
resistir em permanecer como evidências (ainda que fragilizadas), figurando assim, a manutenção do custo social do Turismo.

\section{O Turismo e os seus impactos sobre os valores culturais estabelecidos na comunidade receptora}

O Turismo é uma das atividades contemporâneas que mais apresenta elevação nas suas taxas de desenvolvimento - segundo os dados da Organização Mundial do Turismo (OMT), no período de 2005 a 2013, as viagens internacionais cresceram cerca de $4 \%$ ao ano, o que como consequência, segundo a World Travel \& Tourism Council (WTTC), fez gerar quase três milhões de empregos diretos no mundo, estimando-se que até o ano de 2022, outros quatro milhões sejam acrescidos. Já no Brasil, desde as estatísticas do Ministério do Turismo (MTUR), a atividade representa 3,7\% do Produto Interno Bruto, tendo nestas duas últimas décadas, experimentado um crescimento da ordem de $32,4 \%$, enquanto a economia expandiu-se em cerca de $24,6 \%$. Coriolano (2017, p. 51 ) realça os dados do Banco Central, que com relação aos gastos dos turistas estrangeiros em visita ao país, somaram cerca de sete bilhões de dólares em 2013, assim reforçando a importância do fenômeno junto a geração de novas divisas.

Tudo isto dado, especialmente, o aumento do tempo livre - agora entendido como um tempo social, bem como da renda "per capita" da população dos países desenvolvidos e em vias de desenvolvimento, além das facilidades dos deslocamentos, visto que com a globalização, o mundo ficou menor, logo de acesso substancialmente facilitado. Isto sem falar da tecnologia - cada vez mais notada nos meios de transportes, assim como da mídia, que permanentemente desperta no consumidor, o desejo de conhecer destinos novos a preços tangíveis e condições de pagamento mais elásticas.

Tal prática, portanto, deixa de ser tão somente um "luxo dos mais endinheirados" e passa a compor o orçamento familiar de muitos outros (ao lado da prestação do carro e da reforma do apartamento). Em sendo, graças às demandas consequentemente acrescidas em todo 0 mundo, muitos destinos em maturação se consolidam, ao passo que os potencialmente inclinados passam a ser descobertos pelos ávidos turistas - eles que em realizando as suas viagens, impactam sobremaneira, junto aos núcleos receptores desde os mais diversos substratos, a exemplo daqueles ambiental, econômico e sociocultural. Acerca deste último, Lima (2008, p.75) pontua com toda precisão "[...] se encarrega do estabelecimento acertado de outros costumes, abalando as raízes mais locais", uma vez que altera substancialmente o pacato cotidiano dos moradores, especialmente daqueles mais jovens, sobretudo no que tange aos seus valores, até então mantidos.

São mudanças nas formas de entender o trabalho (com mulheres mais absorvidas neste universo - especialmente a partir do segmento da Hotelaria, além do fluxo migratório dos estrangeiros que abrem novos negócios, inserindo em seus postos, os mais jovens - que se desviculam da dependência econômica dos seus pais). Fonteles (2004, p.155), segue afirmando que "as mulheres, que antes eram donas de casa, passam a 
trabalhar nas pousadas e restaurantes, sendo que outras instalam vendas diversas, em locais onde o turista circula com mais frequência".

Alterações nos hábitos de recreação das crianças, adolescentes e adultos, levando-se em conta que os efeitos da intensa movimentação turística, redesenham também a geografia da cidade, chegando inclusive, a perturbar o ritmo de vida "normal" dos seus habitantes (especialmente naquelas menores - as ruas estreitas passam a ser tomadas pelo tráfego intenso, ao passo que as feiras e as pracinhas, logo se transformam em áreas de estacionamento, dados os inúmeros ônibus de excursões).

Os níveis educacionais também se elevam, permeando a nova disposição estabelecida do - "eu quero ser igual ao visitante culto" e as relações entre gêneros se alteram (agora, mais homens jovens e solteiros podem ser notados, a homoafetividade é mais aceita, bem como a prostituição é, naturalmente, mais evidente).

Os sentimentos de "inveja" são mais observados, de modo particular até mesmo no jeito de vestir (igual aquele do forasteiro "diferente") - o boné, a canga de praia, o "crocs" e o tênis, se constituindo de hábitos de consumo mais inclinados à demonstração dos fluxos (o turista tende a recriar nos locais de destino, as mesmas condições de vida das suas regiões de origem), que passam a se instalar nos fixos, comprometendo assim, os seus reduzidos orçamentos, já tendo sido promovido o que Ruschmann (2002, p.97), reconhece como "ressentimentos, frente à ostentação do tempo livre e do dinheiro, muitas vezes, demasiadamente escassos para os moradores", tudo isto podendo ocasionar relações sociais (inicialmente) conflitantes, figurando em sobremaneira, um território provido de maiores índices de violência, sobretudo entre aqueles de faixa etária menor, que estão, indubitavelmente, mais suscetíveis a estes impactos todos.

Acerenza (2002, p.134) reitera que "[...] o efeito do Turismo sobre a estrutura social varia em função da relação estabelecida entre o número de visitantes e o número de habitantes da área visitada [...]", ainda complementando "[...] visto que o Turismo tido como de maior volume, encoraja expectativas e pautas inapropriadas de consumo para o meio, contribuindo assim para acentuar as diferenças sociais".

E repetindo Wahab (1997), tudo isto se dá, uma vez que o Turismo, sob o seu aspecto conceitual mais subjetivo, entretanto, igualmente intenso (pouco tratado em conceitos próprios, segmentados e clássicos), e em um contraponto aos seus feitos mais notadamente econômicos, vai ao encontro da natural aquisição de conhecimentos novos (nem sempre tão saudáveis) gerados pela interação de povos distintos "in lóco".

Tal realidade abre espaço para o estabelecimento da chamada "Teoria da Alienação no Turismo", ela que tem toda a sua gênese, advinda das críticas marxistas feitas ao capitalismo, e que a partir dos seus autores - John Ash e Louis Turner tratam a atividade, sobretudo aquela com características de massa, como eminentemente degradante, uma vez que despejam todo o "mal" dos países emissores às sociedades mais primitivas receptoras, reconhecidas como "limpas". 
Ratificando toda esta retórica, Rabahy (2003, p.88) conclui que " 0 Turismo, uma vez implantado em um núcleo, pode implicar em mudanças de comportamentos, costumes e mentalidade, eles que se constituem na própria atração do lugar", gerando muitas vezes, inúmeros efeitos não desejáveis, pois culminam com a total descaracterização das raízes históricas e das tradições.

Por outro lado, as diferenças que se estabelecem entre os nativos e os ávidos viajantes - marcadas desde o artesanato, das comidas típicas, das danças, das músicas, permite um considerável enriquecimento para ambos, sendo também, uma forma alternativa e muito funcional do intercâmbio das boas idéias, elas que culminam com o respeito às diferenças dos povos, fortalecendo assim, as suas identidades locais e garantindo a paz entre eles o ideal de maior sentido axiológico do fenômeno turístico.

\section{Material e método utilizados}

\section{O lócus e o universo amostral da pesquisa}

O "lócus" deste trabalho é a cidade de Barreirinhas - precisamente o campus do Instituto Federal do Maranhão, através do seu eixo Hospitalidade, Turismo e Lazer, desde as salas de aulas iniciais (alunos dos primeiro e segundo anos, regularmente matriculados nos tempos letivos 2017.2 e 2018.1) dos cursos técnicos de Agenciamento de Viagens na modalidade Integrado, sendo providas as unidades amostrais (que somam 38 questionários respondidos) da faixa etária compreendida entre 15 a 17 anos, e tendo se constituído estes, como os principais critérios para a definição do universo pesquisado.

\section{O procedimento da coleta dos dados}

Viabilizado com o uso do instrumental investigativo - aplicação de um questionário compacto, estruturado e, sobretudo, acessível (em anexo), concebido de onze (11) perguntas fechadas (múltipla escolha), sendo estas acrescidas de outras duas (02) abertas (mais subjetivas), tendo sido ele, integralmente respondido em um tempo médio de 60 minutos (uma hora) ininterruptos, desde a intervenção do pesquisador, no que tange ao fornecimento coletivo das explicações necessárias (após a leitura em voz alta) de cada uma das indagações componentes (todas em linguagem usual, própria para a idade dos entrevistados - adolescentes), desprezando-se de forma irrestrita, a manifestação pública de quaisquer comentários da parte das unidades amostrais, não inferindo deste modo, conceitos já elaborados de cada uma delas, sobretudo, visto estarmos tratando de aspectos muito particulares, como costumes, tradições e usos.

É válido sublinhar ainda, que os questionários (uma vez respondidos), não foram identificados. 


\section{Resultados obtidos e discussões inerentes}

\section{A análise dos costumes, tradições e usos dos adolescentes da cidade de Barreirinhas (MA): há influências comportamentais dos visitantes?}

Inicialmente questionadas acerca das suas "idades", concluiu-se que 18 das 38 unidades amostrais têm 15 anos; já 16 das 38 unidades amostrais têm 16 anos, e por fim, 04 das 38 unidades amostrais têm 17 anos, sendo que nenhuma delas tem idade inferior a 15 anos e superior a 17 anos.

O Quadro 1, evidencia os percentuais relacionados.

Quadro 1: Idade das unidades amostrais da pesquisa.

Table 1: Sign unities of the study's age.

\begin{tabular}{|c|c|c|}
\hline Resposta & $\begin{array}{c}\text { Quantidade das } \\
\text { Unidades Amostrais }\end{array}$ & $\begin{array}{c}\text { Percentual } \\
\text { Relacionado }\end{array}$ \\
\hline 15 anos & 18 & $47,37 \%$ \\
\hline 16 anos & 16 & $42,10 \%$ \\
\hline 17 anos & 04 & $10,52 \%$ \\
\hline
\end{tabular}

Fonte: autores (2018)

Source: authors (2018).

Seguindo a dinâmica do questionário, propôs-se uma outra indagação: "Você tem interesse de aprender com os artesãos locais, as inúmeras técnicas do trançado do buriti? - elas que respondem pela produção do rico artesanato da região", questão esta, imediatamente seguida de duas possibilidades pontuais de respostas (sim ou não), sendo que, de pronto, já suscitava as necessárias justificativas.

Daí então, se observou que das 38 unidades amostrais, 28 (73,68\% do universo pesquisado) afirmam ter interesse neste aprendizado, atribuindo a ele conceitos diversos, a exemplo de bonito, relaxante, tradicional, útil para quem o produz, visto que traz o sustento e movimenta a economia, sendo um modo de ganhar dinheiro e, sobretudo, de manter a cultura local viva.

Figurando novas frentes de importância produtiva, o artesanato, que é fonte de trabalho e renda para mais de oito milhões de brasileiros, em Barreirinhas é uma realidade encaminhada pela mesma força laboral, que 0 Casasola (2003, p.64) postula existir em outros destinos "[...] mulheres, seus filhos e maridos, estes últimos em época de inatividade agrícola", sendo que na cidade, a maioria deles permanece mais organizados, em associações e cooperativas, no intento de maximizar a gestão da atividade, dando um sentido mais pleno de valor ao objeto do seu trabalho.

A partir de Buriti (2010, p.5), em um catálogo de produtos do Serviço Brasileiro de Apoio a Micro e Pequena Empresa (SEBRAE), as gestoras do então projeto Comércio Justo e Solidário do Artesanato Maranhense da Fibra do Buriti, sublinham "A prática do trabalho artesanal assegura aos núcleos, a possibilidade concreta de inclusão social, geração de renda e desenvolvimento sustentável para cada um". E tudo em uma região, que detém os mais baixos Índices de Desenvolvimento Humano (IDH) do país.

Já as outras 10 unidades amostrais (26,31\% do universo pesquisado) revelaram que não têm interesse nele, justificando-se, dentre outras coisas, 
através da inexistência do dom (muitos também falam da paciência) para labores manuais e do reconhecimento de que é trabalhoso, encarregando-se de ceder lugar para as novas tecnologias. resposta.

O Gráfico 1, de modo mais didático, se encarrega de ilustrar tal

Gráfico 1: Você tem interesse de aprender com os artesãos locais, as inúmeras técnicas do trançado do buriti? - elas que respondem pela produção do rico artesanato da região

Graphic 1: Do you have interest to know with the local artisans the diferents technics of the burit tressed? - the rich regional workmanship.

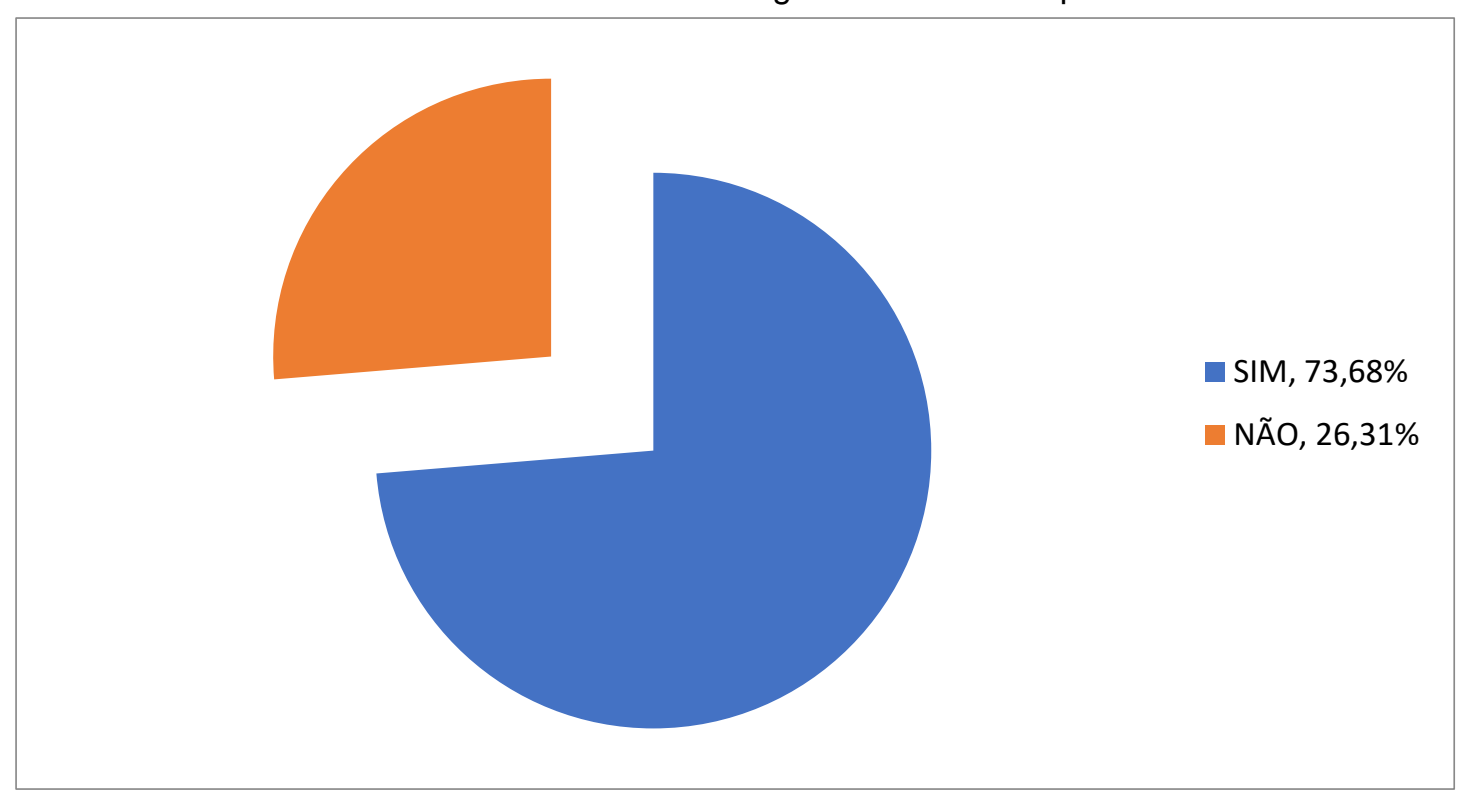

Fonte: autores (2018).

Source: authors (2018).

A pergunta próxima trata de uma condicionante, criando para tanto, uma situação problema, a saber: "E se o sol está forte, e você precisa ir à farmácia (já um pouco gripado), como então protegerá a sua cabeça?” Diante dela, todas as unidades amostrais (100\%), responderam de modo unânime, que usariam "um boné (de grife) que um amigo turista lhe presentou".

A resposta equidistante "com um chapéu (de palha) que o seu pai usa para pescar", fôra ignorada pela totalidade do universo pesquisado, tudo isto evidenciando, portanto, a descomunal força do "efeito imitação" a que os fixos (especialmente, os mais jovens) ficam vulneráveis desde a chegada (e permanência) dos fluxos, passando então, a desconsiderar as suas mais tenras identidades.

$\mathrm{Na}$ sequência, o questionário provoca discussões inerentes aos costumes, quando então, desenha a pergunta de número 4: "Você tem o hábito de tirar uma soneca, depois do almoço?", tendo se concluído que 29 das 38 unidades amostrais respondem "sim - o tempo ainda passa muito devagar por aqui"; ao passo que 09 das 38 unidades amostrais respondem "não - não existe mais tempo para isto, em Barreirinhas". 
O Quadro 2, evidencia os percentuais relacionados.

Quadro 2: Você tem o hábito de "tirar uma soneca", depois do almoço?

Table 2: Do you have the habit "to take a nap" afther the lunch?

\begin{tabular}{|c|c|c|}
\hline Resposta & $\begin{array}{c}\text { Quantidade das } \\
\text { Unidades Amostrais }\end{array}$ & $\begin{array}{c}\text { Percentual } \\
\text { Relacionado }\end{array}$ \\
\hline $\begin{array}{c}\text { Sim - o tempo ainda passa muito } \\
\text { devagar por aqui }\end{array}$ & 29 & $76,31 \%$ \\
\hline $\begin{array}{c}\text { Não - não existe mais tempo para } \\
\text { isto em Barreirinhas }\end{array}$ & 09 & $23,68 \%$ \\
\hline
\end{tabular}

Fonte: autores (2018).

Source: authors (2018).

Tais evidências comportamentais seguramente se explicam, desde a tradição que remete aos mais antigos comerciantes do lugar - eles que ainda cultivam a prática (provinciana) de fechar as suas portas depois do meio dia, visto o descanso do almoço e o forte calor que se instala nestas horas.

Desde isto, Lima (2008, p.59), fala que "Os habitantes do município, ainda guardam muito das suas tradições culturais", sendo o conflito do antigo com o novo, do velho com o jovem, o que se estabelece com muita nitidez.

A indagação de agora retoma as questões inerentes ao uso (a exemplo daquela de número 3 do questionário), sendo ela, portanto: " $E$ para passear, em um fim de semana na beira rio, observando o movimento dos turistas que voltam dos seus passeios - o que você prefere usar?" As respostas contabilizaram que das 38 unidades amostrais, $32(84,21 \%$ do universo pesquisado) escolhem uma sandália do tipo "havaiana"; sendo que somente $03(7,89 \%$ do universo pesquisado) optam por um chinelo (plástico) do tipo "crocs". As outras 03 unidades amostrais restantes (também 7,89\% do universo pesquisado) escolheram um tênis (de grife).

É importante ratificar que nenhuma das 38 unidades amostrais pesquisadas interessou-se pelo passeio, fazendo uso de um tamanco do tipo "chamató" (com base em madeira e tiras de couro), vendido apenas no mercado da cidade - sem dúvidas, a mais autêntica das opções de calçados ofertada.

O Gráfico 2 (próxima página), de modo mais didático, se encarrega de ilustrar tal resposta.

Provocadas desde a pergunta de número 6, "Ainda acerca do fim de tarde - com que freqüência você observa sua mãe, avó e vizinhas, sentadas em cadeiras de embalo de macarrão, nas portas das suas casas, conversando amenidades? concluiu-se que 02 das 38 unidades amostrais responderam "Nunca observei - o trânsito intenso e a violência constante não permitem isto"; já 19 das 38 unidades amostrais responderam "Muito raramente observo - minha mãe e suas vizinhas agora trabalham fora", e por fim, 17 das 38 unidades amostrais responderam "Sempre observo".

O Quadro 3, evidencia os percentuais relacionados. 
Gráfico 2: E para passear, em um fim de tarde na Beira Rio, observando o movimento dos turistas que voltam dos seus passeios - o que você prefere usar?

Graphic 2: And for walk, one end of the afternoon at Beira Rio, looking for the tourists' movement which return of theirs tours - What do you prefer to use?

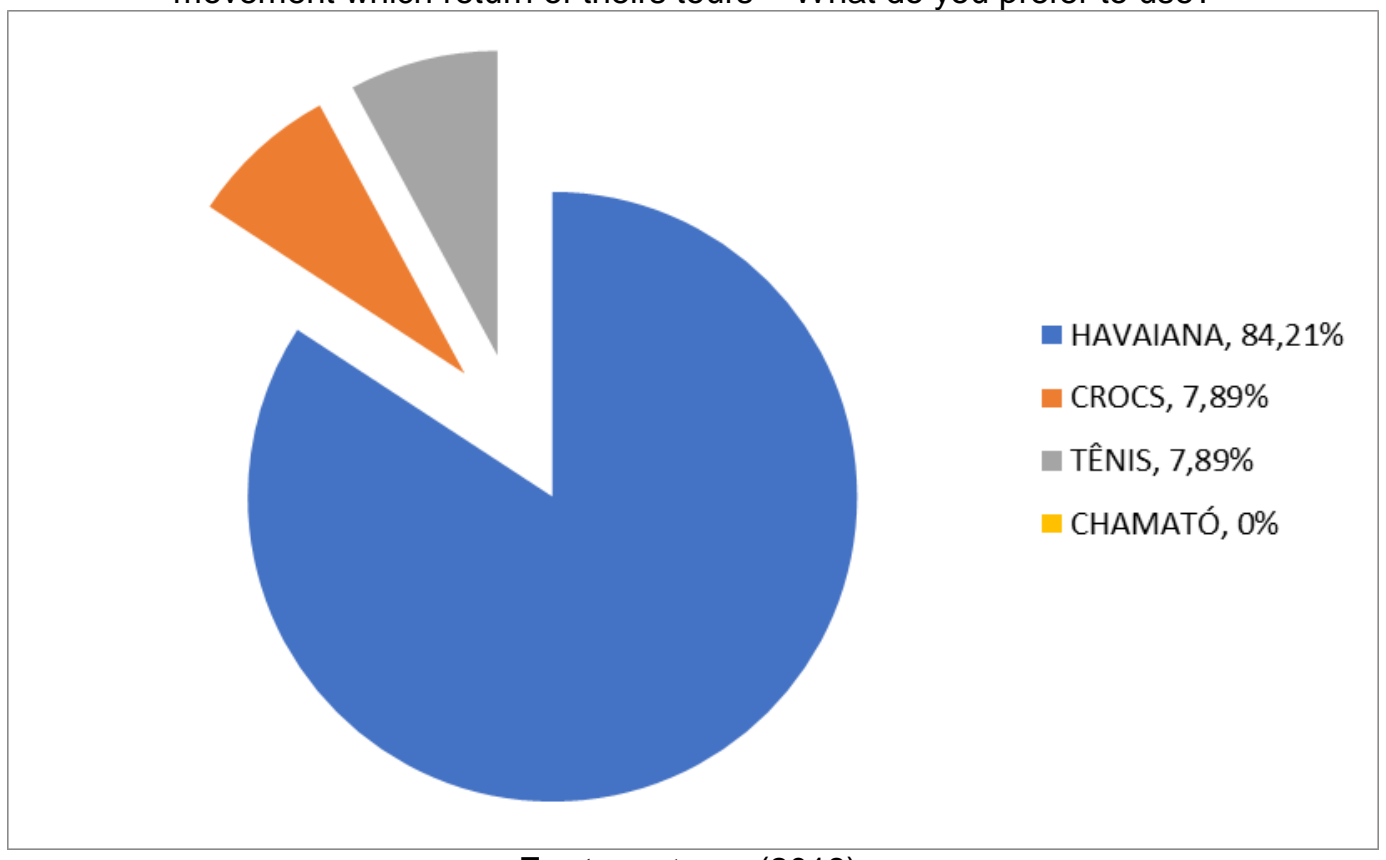

Fonte: autores (2018).

Source: authors (2018).

Quadro 3: Ainda acerca do fim de tarde - Com que freqüência você observa sua mãe, avó e vizinhas, sentadas em cadeiras de embalo de macarrão, nas portas das suas casas, conversando amenidades?

Table 3: Still about end of the afternoon - What frequency you look your mother, grandmother and neighbours, place on a seat, near the doors of theirs houses, talking amenities?

\begin{tabular}{|c|c|c|}
\hline Resposta & $\begin{array}{c}\text { Quantidade das } \\
\text { Unidades Amostrais }\end{array}$ & $\begin{array}{c}\text { Percentual } \\
\text { Relacionado }\end{array}$ \\
\hline Nunca observei & 02 & $5,26 \%$ \\
\hline $\begin{array}{c}\text { Muito raramente } \\
\text { observo }\end{array}$ & 19 & $50 \%$ \\
\hline Sempre observo & 17 & $44,73 \%$ \\
\hline
\end{tabular}

Fonte: autores (2018).

Source: authors (2018).

Assim é possível concluir que justificativas factuais, também aplicadas a territorialidade da cidade de Barreirinhas, são todas conseqüências da atividade turística consolidada (e já amplamente tratadas neste estudo) - e a exemplo do trânsito que se intensifica e da violência mais manifestada, bem como das possibilidades mais notadas de trabalho feminino fora do lar, mexem (de modo muito considerável) com antigos costumes domésticos, o que de todo impacta nas relações familiares de tais adolescentes.

O questionamento de número 7 trata das preferências relativas aos hábitos alimentares: "Com fome, logo à noite, o que você prefere lanchar?" Em sendo, observou-se que das 38 unidades amostrais, 12 (31,57\% do universo pesquisado) preferem o regionalismo de "um suco de caju do quintal, e depois um café com tapioca quentinhos, feitos pela vovó"; ao passo que 26 
unidades amostrais $(68,42 \%$ do universo pesquisado) preferem a universalidade (muitas vezes imposta) da "Coca-cola e um sanduíche montado no Subway (lanchonete fast food presente em todo o mundo) da Beira Rio, junto dos turistas".

Avançando, o questionário instiga-se acerca de que modo os adolescentes pesquisados, fazem uso do seu tempo livre, lançando então a pergunta: "Como lazer no domingo, você prefere o quê?" A resposta "Um refrescante banho no rio Preguiças com os amigos", soma 31 das 38 unidades amostrais $(81,57 \%$ do universo pesquisado), sendo bastante provável, portanto, que tal prática se constitua em mais uma possibilidade de observação dos visitantes, e até mesmo de interação com estes, já que o rio é, em sobremaneira, um espaço turistificado. A resposta "Ficar em casa, vendo TV e baixando alguns aplicativos no celular", soma 07 das 38 unidades amostrais (18,42\% do universo pesquisado).

Já a pergunta de número 9 assim se figura: " $E$ de presente de aniversário para uma amiga da escola, você compraria o quê?" Desde ela, concluiu-se que das 38 unidades amostrais, apenas 03 (7,89\% do universo pesquisado) optam por "uma bolsa de palha macramê, feita pelas artesãs cooperadas". Entretanto, 35 unidades amostrais (92,10\% do universo pesquisado) optam por "um perfume do O Boticário (marca de cosméticos das mais populares do país)".

Em Barreirinhas, especialmente nas comunidades de Bonito, Manoelzinho e Vigia, o "macramê" - técnica de tecelagem manual, adaptada a fibra do buriti é muito trabalhada. Fibras (2012, p.21), o detalha a partir de "Filamentos de linho, separados de acordo com suas espessuras e tamanhos, sendo a trança executada com o auxílio de fôrmas de madeira, cortadas desde o modelo do produto a ser feito".

A quase unanimidade da resposta dada à pergunta em questão, só ratifica aquela outra (inicial) de número 2 , onde $73,68 \%$ dos adolescentes renegam o interesse pelo aprendizado das técnicas do trançado do fruto da palmeira regional.

Depois, assim questionados: "Já para ajudar nos seus deslocamentos aqui na cidade, qual destas mobilidades então optaria por comprar?", os jovens pesquisados se mostram bem certos das suas escolhas. Tais respostas contabilizaram que das 38 unidades amostrais, 09 (23,68\% do universo pesquisado) escolhem comprar a "bicicleta"; a grande maioria, 29 das 38 unidades amostrais $(76,31 \%$ do universo pesquisado) escolhem comprar os motorizados "jet ski, motocicleta e quadriciclo", se constituindo da preferência dos habitantes do lugar, as motos (elas, em 2014, segundo o IBGE, somavam quase 4 mil, sendo que muitas permanecem a serviço dos trabalhos do tipo mototáxi).

É válido observar, que nenhuma das unidades amostrais escolheram comprar a "canoa" - o que para elas, se constitui de um modal completamente distante, visto muito primitivo, e logo, desprovido de quaisquer interesses. resposta.

O Gráfico 3, de modo mais didático, se encarrega de ilustrar tal 
Gráfico 3: Já para ajudar nos seus deslocamentos aqui na cidade, qual destas mobilidades então optaria por comprar?

Graphic 3: For help you on your displaces here in the city, which of these mobilities you choose to buy?

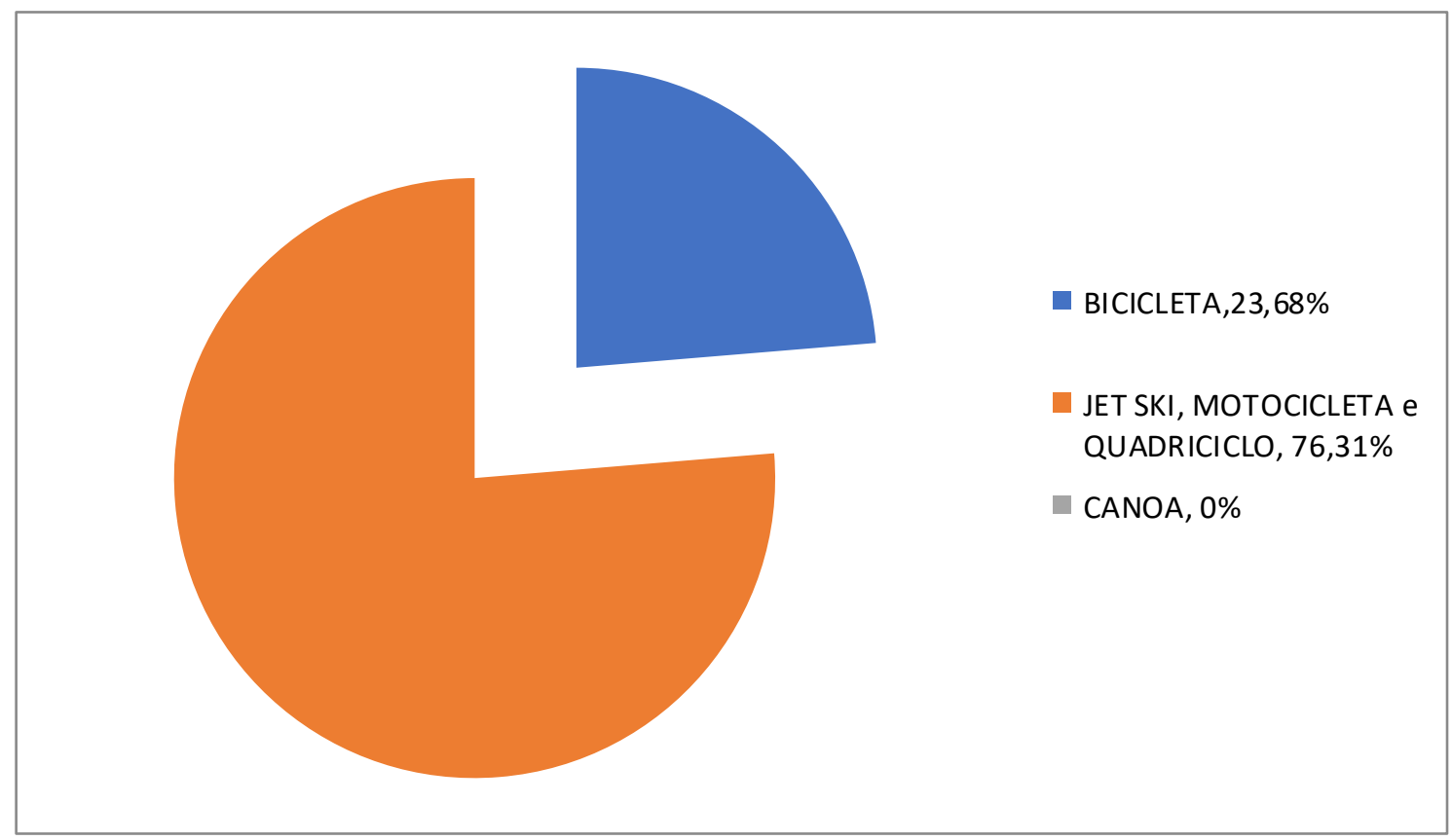

Fonte: autores (2018).

Source: authors (2018).

Finalizando a parte mais objetiva da pesquisa - ela que se constitui das onze primeiras perguntas do questionário instrumental, indagou-se (mais uma vez de forma condicionante): "E se você resolvesse trabalhar agora - em qual destes segmentos buscaria uma vaga?" 18 das 38 unidades amostrais falaram querer trabalhar no "Serviço Público - ia me empregar em algum órgão da prefeitura"; já 20 das 38 unidades amostrais falaram querer laborar no "Turismo - ia trabalhar em um hotel". Por fim, nenhuma das unidades amostrais manifestou o desejo de trabalhar na "Agricultura" e na "Pecuária" atividades historicamente presentes no município de Barreirinhas, antes mesmo do estabelecimento do fenômeno turístico, notadas, sobretudo, desde o cultivo da castanha de caju, da fabricação artesanal da farinha de mandioca e da pesca.

O Quadro 4, evidencia os percentuais relacionados.

Quadro 4: E se você resolvesse trabalhar agora - em qual destes segmentos buscaria uma vaga?

Table 4: And if you resolve to work now - which segment do you choose?

\begin{tabular}{|c|c|c|}
\hline Resposta & $\begin{array}{c}\text { Quantidade das } \\
\text { Unidades Amostrais }\end{array}$ & $\begin{array}{c}\text { Percentual } \\
\text { Relacionado }\end{array}$ \\
\hline Serviço Público & 18 & $47,37 \%$ \\
\hline Turismo & 20 & $52,63 \%$ \\
\hline $\begin{array}{c}\text { Agricultura e } \\
\text { Pecuária }\end{array}$ & 00 & - \\
\hline
\end{tabular}

Fonte: autores (2018).

Source: authors (2018). 
Agora, incitado a responder questionamentos mais abertos (subjetivos), lança-se ao universo pesquisado, a primeira de uma série de duas: "Você se identifica com os turistas que nos visitam? $O$ que eles têm de tão interessante?" Das 38 unidades amostrais, 20 responderam que "Sim" (52,63\% do universo pesquisado), e de modo bastante equilibrado, 18 delas (47,37\% do universo pesquisado) responderam que "Não".

Fundamentando tais respostas, os adolescentes assim completaram: "Os costumes (mais avançados) dos visitantes são interessantes - o gosto deles pela tecnologia é atraente"; "Como gosto de culturas diferentes (especialmente, a oriental), me identifico com eles"; "... Os turistas são curiosos, e eu também sou"; "Observo como eles falam (sotaque carregado) e o modo de como eles se vestem - me arrumo parecido com eles"; "...Trazem novidades e olham a cidade com mais fascínio, querendo aprender coisas novas"; "São bem exigentes - se não está bom, reclamam logo".

Em contrapartida, outras respostas claramente denotam uma relativa adversidade do nativo para com o forasteiro - até uma certa repulsa, podendo elas serem sintetizadas nesta, que segue: "Nada me chama atenção neles se acham sempre superiores a nós que vivemos aqui".

O instrumental investigativo então se encerra, propondo aos adolescentes, uma indagação/consequência ainda mais reflexiva, portanto: "Você entende que a chegada dos turistas em nossa cidade, altera nossos costumes, tradições e usos?" Das 38 unidades amostrais, todas elas (sem exceção alguma), responderam que "Sim" (100\% do universo pesquisado).

Em sequência a tal pergunta (compondo-a, inclusive), situações que tornam esta realidade ainda mais evidente, são solicitadas para uma mostra, tendo os entrevistados, conclusivamente, assim respondido: “... Existe um aumento na criminalidade - as janelas das nossas casas já ficam mais fechadas (com cadeados e grades) e os nossos vizinhos já não sentam mais nas suas portas para conversar"; "... As lojas abrem até mais tarde da noite, aguardando o retorno dos turistas dos seus passeios", sendo o que Ruschmann (1997, p.19), já aqui desenhou como "novas oportunidades de emprego, trabalho e renda". Os pesquisados ainda acrescentam "... As pessoas que vivem aqui passam a se vestir de maneira mais parecida com 0 visitante - imitando eles", e mais uma vez, aproximando-se de Yázigi (2003, p.127), quando aborda o que reconhece como a "pressa em ganhar dinheiro com o forasteiro", finalizam em observação "... Ninguém quer mais trabalhar com a agricultura e a pesca, visto que com o Turismo, o dinheiro é mais fácil e maior".

\section{Conclusões}

No intento da proposição matricial desta pesquisa - portanto, responder a indagação "Costumes, tradições e usos dos adolescentes da cidade de Barreirinhas/MA... Há influências comportamentais dos visitantes?" é possível concluir, sob uma percepção mais ampliada, munida de bastante cientificidade (visto as metodologias quantitativa e qualitativa), resultante das 38 unidades amostrais tratadas, que a exemplo do que acontece em outros 
destinos turísticos consolidados (ou ainda, em vias de consolidação), os jovens que se constituem de uma faixa etária menor (15 a 17 anos) permanecem seguramente mais vulneráveis a descomunal força do "efeito imitação" que se estabelece (mesmo que de modo não provocado) desde a chegada e permanência dos fluxos (turistas), passando muitas vezes, a desconsiderar as suas mais tenras identidades, os seus "sítios de pertencimento" - eles que se constituem da própria atração do lugar (talvez da maior), manifestando quase sempre, o desejo de ser parecido com os visitantes, entendidos como "abastardos e cultos", eles que se vestem e falam de um jeito bem diferente.

Outras variantes, agora mais aplicadas à territorialidade da cidade como o trânsito que se intensifica, a violência que se manifesta e as sucessivas possibilidades (mais notadas) de trabalho feminino fora do lar, mexem de modo muito considerável com antigos modos domésticos, o que de todo impacta nas relações familiares (e de amizades) destes adolescentes atores deste estudo científico, precisamente, visto as rotinas que se alteram, bem como as percepções, os valores, os sentimentos estabelecidos (a inveja, frente a ostentação dos fluxos gera cobranças) e até os vínculos (que tendem a tornarem-se mais fragilizados, em função de uma maior independência financeira).

Portanto, como prevíamos nos tratos introdutórios desta abordagem, os resultados obtidos desde o estudo proposto, notadamente apontam para as evidências de uma situação entendida como afirmativa - logo, os costumes, tradições e usos dos adolescentes da cidade de Barreirinhas/MA, estão suscetíveis as influências comportamentais dos visitantes.

Por fim, faz-se necessário realçar toda a importância do trabalho em questão, visto o seu caráter absolutamente inovador (naquilo a que se propõe), ele que nos faz repensar no considerável valor estabelecido pelo "diferente", especialmente junto ao público estudado - que está em construção das suas existências axiológicas, sejam elas cognitivas ou emocionais; como também nos sinaliza (sobretudo, a nós educadores e militantes do fenômeno do Turismo) para a perene necessidade de fomentar nele, aquilo que é nosso, o tal do "orgulho instalado", o que nos está arraigado em ideias e práticas.

\section{Referências}

ACERENZA, M.A. Administração do turismo: conceituação e organização. Bauru, SP: EDUSC, 2002.

BURITI do Maranhão. Catálogo de Produtos. São Luís: Sebrae, 2010.

CASASOLA, L. Turismo e ambiente. São Paulo: Roca, 2003.

CORIOLANO, L.N. et al. Turismo e prática de responsabilidade socioambiental em empreendimentos turísticos no Nordeste brasileiro. Fortaleza: BNB, 2017.

FIBRAS e tramas de Barreirinhas. Rio de Janeiro: IPHAN, CNFCP, 2012. (Sala do Artista Popular, n. 178). 
FONTELES, J.O. Turismo e impactos socioambientais. São Paulo: Aleph, 2004.

INSTITUTO BRASILEIRO DE GEOGRAFIA E ESTATÍSTICA - IBGE. Brasília, 2015. Disponível em: <www.cidades.ibge.gov.br>. Acesso em: 02 out. 2016.

LIMA, J.M.B. As belezas e os mistérios do rio Preguiças: Lençóis maranhenses, explosão de vida. Barreirinhas - MA, 2008.

RABAHY, W. A. Turismo e desenvolvimento: estudos econômicos e estatísticos no planejamento. Barueri, SP: Manole, 2003.

RAMOS, B. História de Barreirinhas: portal dos Lençóis Maranhenses. São Luís, 2008.

RUSCHMANN, D. Turismo e planejamento sustentável: a proteção do meio ambiente. Campinas, SP: Papirus, 1997.

WAHAB, S.E. Introdução à administração do turismo. São Paulo: Pioneira, 1977.

Marcelo Aragão Saldanha: Instituto Federal do Maranhão, Barreirinhas, MA, Brasil.

E-mail: marcelo.saldanha@ifma.edu.br

Link para o currículo Lattes: http://lattes.cnpq.br/7157840590052692

Leonardo Augusto Lobato Bello: Universidade da Amazônia, Belém, PA, Brasil.

E-mail: leonardo.bello@unama.br

Link para o currículo Lattes: http://lattes.cnpq.br/5449459117793556

Sílvia Helena Ribeiro Cruz: Universidade Federal do Pará, Belém, PA, Brasil.

E-mail: silhcruz@gmail.com

Link para o currículo Lattes: http://lattes.cnpq.br/8432421463410679

Data de submissão: 27 de junho de 2018

Data de recebimento de correções: 31 de julho de 2018

Data do aceite: 31 de julho de 2018

Avaliado anonimamente 